\title{
PCA: UMA FERRAMENTA PARA IDENTIFICAÇÃO DE TRAÇADORES QUÍMICOS PARA ÁGUA DE FORMAÇÃO E ÁGUA DE INJEÇÃO ASSOCIADÁS À PRODUÇÃo DE PETRÓLEO
}

Fabiana Alves de Lima Ribeiro ${ }^{*, \#}$, Guilherme Alvarenga Mantovani ${ }^{\#}$ e Ronei Jesus Poppi ${ }^{\#}$

Instituto de Química, Universidade Estadual de Campinas, Cidade Universitária Zeferino Vaz, CP 6154, 13083-970 Campinas SP, Brasil

Francisca Ferreira do Rosário, Maria Carmen Moreira Bezerra, Andre Luis Mathias Bastos e Vera Lúcia Alves de Melo Centro de Pesquisas e Desenvolvimento Leopoldo Américo Miguez de Mello, Petróleo Brasileiro S.A., Av. Horácio Macedo, 950 - Cidade Universitária, 21941-915 Rio de Janeiro - RJ, Brasil

Recebido em 8/1/13; aceito em 24/6/13; publicado na web em 2/8/13

\begin{abstract}
PCA: A TOOL FOR IDENTIFICATION OF CHEMICAL TRACERS FOR FORMATION AND INJECTION WATERS ASSOCIATED WITH OIL PRODUCTION. This study describes the use of Principal Component Analysis to evaluate the chemical composition of water produced from eight oil wells in three different production areas. A total of 609 samples of produced water, and a reference sample of seawater, were characterized according to their levels of salinity, calcium, magnesium, strontium, barium and sulphate $\left(\mathrm{mg} \mathrm{L}^{-1}\right)$ contents, and analyzed by using PCA with autoscaled data. The method allowed the identification of variables salinity, calcium and strontium as tracers for formation water, and variables magnesium and sulphate as tracers for seawater.
\end{abstract}

Keywords: produced water; PCA; exploratory analysis.

\section{INTRODUÇÃO}

O petróleo como fonte de energia exerce um papel essencial na economia produtiva mundial, e os países que detêm a sua produção e distribuição apresentam destacado desempenho econômico em setores vitais, tais como transporte, indústria e geração de energia, além de serem responsáveis pelo abastecimento do mercado internacional. ${ }^{1,2} \mathrm{~A}$ produção nacional de petróleo alcançou em 2006 a sua auto-suficiência, quando a empresa Petrobrás (Petróleo Brasileiro S.A.) atingiu a sua maior produção até aquele momento, com o maior lucro obtido em toda a sua história e nos últimos 20 anos entre as empresas de capital aberto da América Latina. Esse fato impulsionou a economia nacional, causando forte impacto no mercado internacional de petróleo. ${ }^{2,3}$

Ainda em 2006, foi anunciada a descoberta de indícios da existência de jazidas de petróleo na camada do pré-sal na Bacia de Santos, localizada nas profundezas do leito marinho abaixo da camada geológica de sal. Essa descoberta foi posteriormente confirmada em 2007, iniciando-se então um intenso debate a respeito da regulação da exploração do petróleo nacional, e impulsionando os investimentos da empresa nesta área. ${ }^{1,4}$

Em 2012 a Petrobrás investiu 84,01 bilhões de reais na extração do óleo, atingindo uma produção de petróleo, líquido de gás natural (LGN) e gás natural da ordem de 2,4 milhões de barris por dia (bpd), dos quais, 300 mil bpd foram extraídos da camada do pré-sal. Entre Janeiro/2012 e Fevereiro/2013, 53 novas reservas de petróleo foram descobertas pela empresa, dentre as quais 25 encontram-se no mar e 28 em terra, sendo que das 25 reservas marítimas, 15 estão localizadas na camada do pré-sal. ${ }^{2,5}$ Esses resultados transformaram a Petrobrás na líder mundial na exploração de petróleo em águas profundas, e representam uma significativa contribuição para a economia brasileira, colocando o Brasil num patamar de destaque no cenário econômico mundial.

Os principais desafios tecnológicos para a exploração do petróleo na camada do pré-sal foram vencidos, e estão associados principalmente

*e-mail: falribeiro@gmail.com

"Laboratório de Quimiometria em Química Analítica aos estudos sísmicos da região para otimizar o sucesso exploratório; à modelagem geológica e numérica, para melhor previsão do comportamento da produção; redução do tempo de perfuração; seleção de novos materiais visando a redução do custo da perfuração; qualificação de novos sistemas para coleta da produção, visando maior competitividade; separação do $\mathrm{CO}_{2}$ do gás natural em águas profundas e reinjeção, visando a redução das emissões e aumento do fator de recuperação. ${ }^{5}$

Durante a produção do petróleo é gerada uma mistura de águas de diferentes origens, conhecida como água produzida, cuja composição química ainda é pouco conhecida, e sua caracterização representa um dos desafios tecnológicos ainda a serem vencidos devido às dificuldades associadas à sua amostragem. Dependendo da composição química da água produzida, esta poderá favorecer a formação de precipitados salinos que poderão se depositar nas tubulações dos poços de coleta formando incrustações de difícil remoção, ocasionando paradas ou danos ao processo, com impactos significativos nos custos e tempo da produção. ${ }^{6}$

\section{Água produzida}

A água produzida é essencialmente resultado da mistura da água de injeção com a água naturalmente presente no reservatório, que por sua vez é uma mistura da água de formação e da água do aquífero. O percentual de água produzida é dependente da geologia do reservatório e da estratégia de explotação do campo, e pode ser descrita em função da sua composição química e consequentes propriedades físico-químicas. ${ }^{7-13}$

A água de injeção é a água utilizada na recuperação do petróleo, que pode ser proveniente de aquíferos subterrâneos, da própria água produzida recuperada ou da água do mar. Esta última alternativa tem sido a mais utilizada nas plataformas de alto mar, devido à sua disponibilidade e viabilidade econômica. ${ }^{7,11,12,14} \mathrm{~A}$ água de formação, também conhecida como água conata, é a água naturalmente associada aos reservatórios de petróleo no tempo geológico. Sua amostragem é extremamente difícil, pois se encontra emulsionada na fase oleosa em quantidades muito pequenas (até $0,5 \%$ de sedimentos e água no fluído produzido), o que compromete a sua quantificação. Por esse 
motivo, sua composição química é pouco estudada, e na maioria dos estudos considera-se que seja semelhante à composição química do aquífero. ${ }^{7,11,12}$ Durante bilhões de ano essa água ficou em contato com o fluido do reservatório e, portanto, assume-se que o gás produzido encontra-se saturado com vapor de água. Durante as variações de pressão e temperatura ocorridas durante o processo de produção de petróleo, essa água de saturação poderá evaporar ou condensar, influenciando o escoamento de fluidos, principalmente em campos produtores de gás. Essa água associada à produção de gás tem características de água doce, pois é proveniente de água evaporada. ${ }^{7,11,12,14}$ A água proveniente dos aquíferos subterrâneos apresenta composição química semelhante à rocha-reservatório, mas em geral contém altos níveis de salinidade, que aumentam com a profundidade. ${ }^{7,11,12,14}$

O conhecimento da composição da água produzida e de suas águas constituintes, em especial as frações de água de formação e água de injeção, é importante para o entendimento do comportamento do fluxo e drenagem do reservatório produtor e ainda na previsão da composição de água que alcançará o poço produtor. A água do mar, geralmente utilizada como água de injeção, é rica em sulfato e carbonato, enquanto a água de formação é rica em cátions precipitantes como bário, estrôncio e cálcio. Essa composição característica das duas águas poderá gerar incompatibilidade entre elas, uma vez que sua mistura tende a formar precipitados salinos de baixa constante de dissociação nos reservatórios, favorecendo a formação de incrustações nas tubulações, mencionada anteriormente. ${ }^{6-8,12}$

\section{Caracterização da água produzida}

O conhecimento da composição química das duas frações é crucial para a prevenção da formação destes precipitados salinos, mas devido às limitações tecnológicas na amostragem da água de formação, que resultam na sua contaminação por filtrado de fluidos de perfuração e completação, é impossível determinar com precisão analítica a sua porcentagem na água produzida..$^{7-9,12,15,16}$ Apesar dessas limitações, a interpretação da composição química da água produzida em si poderá fornecer valiosas informações a respeito dessas frações e, portanto, sobre o comportamento físico-químico do poço durante a extração do óleo. ${ }^{7-9,16-20}$ Monitoramentos univariados utilizando séries temporais, correlação entre variáveis e distribuição espacial têm sido empregados rotineiramente para acompanhar as variações na composição química da água produzida e na identificação de irregularidades no processo de extração do óleo. No entanto, essa abordagem é limitada, pois não considera a interação entre fatores. ${ }^{7,20-24}$ Métodos multivariados, em especial a Análise de Componentes Principais (PCA, do inglês para Principal Component Analysis) para casos exploratórios, e a Regressão por Mínimos Quadrados Parciais (PLS, de Partial Least Square) para a modelagem de variáveis independentes, têm sido utilizados com sucesso na avaliação da composição química da água produzida, como alternativa aos métodos univariados. ${ }^{7,10,15,16,20-22}$ Essa estratégia tem se mostrado mais adequada, pois permite a avaliação sistemática de todos os parâmetros químicos simultaneamente, e a identificação de espécies, ou relação entre espécies, que possam ser utilizados como traçadores para as águas de formação e de injeção. Essas técnicas são capazes de detectar agrupamentos entre amostras com composição química similar e identificar amostras com comportamento atípico, bem como identificar as variáveis químicas que caracterizam este comportamento.

\section{PCA, PARAFAC: interpretação da composição química da água produzida}

Recentemente a Análise de Fatores Paralelos (PARAFAC, de Parallel FACtor analysis), uma extensão do PCA para dados de ordem superior, foi utilizada com sucesso para a análise exploratória de amostras de água produzida coletadas em 8 poços produtores de petróleo com periodicidade mensal durante os anos de 2004 e $2005{ }^{25}$ O conjunto de dados utilizado naquele caso é resultado de um estudo preliminar do presente trabalho, no qual foram analisadas 23 amostras (coletadas entre janeiro e dezembro dos anos de 2004 e 2005) $\times 6$ variáveis $\times 8$ poços produtores, o que permitiu concatenar as amostras em uma estrutura tridimensional, capaz de ser analisada pelo método PARAFAC, que representa uma das melhores alternativas para a análise exploratória desse tipo de arranjo de dados.

No presente trabalho foi realizado um estudo mais abrangente, com amostras coletadas nos mesmos poços produtores entre agosto de 2002 e maio de 2008, durante as operações de rotina dos poços para extração do óleo oriundos de três diferentes zonas de produção, totalizando 609 amostras estudadas. No entanto, essas coletas não apresentaram periodicidade mensal durante o período investigado e para todos os poços simultaneamente, tendo ocorrido somente durante a atividade dos mesmos, resultando em lacunas no conjunto de dados que impossibilitam concatenar as amostras de forma a obter um arranjo tridimensional capaz de ser analisado por um método de ordem superior. Como alternativa, organizamos os resultados no formato de uma matriz $\mathbf{X}(I, J)$ com $I=609$ amostras de água produzida proveniente dos poços investigados e no período descrito acima, e $J=6$ variáveis químicas analisadas (teores de salinidade, cálcio, magnésio, estrôncio, bário e sulfato $\left(\mathrm{mg} \mathrm{L}^{-1}\right)$, cuja análise exploratória foi realizada utilizando o método PCA. ${ }^{26,27}$ A análise permitiu identificar traçadores para as águas de formação e injeção, além de agrupamentos de amostras relacionados aos diferentes poços produtores e padrões relacionados à sazonalidade para os poços que receberam injeção de água do mar.

\section{PARTE EXPERIMENTAL}

\section{Conjunto de dados}

O conjunto de dados estudado é formado por amostras de água produzida oriunda de 8 poços produtores de petróleo, coletadas no período entre agosto de 2002 e maio de 2008, conforme descrito na Tabela 1 .

Tabela 1. Período de coleta para as amostras de cada poço produtor

\begin{tabular}{cccccccc}
\hline Poço & 2002 & 2003 & 2004 & 2005 & 2006 & 2007 & 2008 \\
\hline P-01 & - & x & x & x & x & x & x \\
P-06 & x & x & x & x & x & - & - \\
P-07 & x & - & x & x & x & - & - \\
P-10 & - & x & x & x & x & x & x \\
P-13 & - & x & x & x & - & - & x \\
P-15 & - & - & x & x & x & x & x \\
P-17 & x & x & x & x & x & x & x \\
PR-02 & x & x & x & x & x & x & x \\
\hline
\end{tabular}

(-) dados não disponíveis. (x) coleta efetuada.

As coletas foram realizadas durante as operações de rotina dos poços, e não foram realizadas em datas simultâneas para todos os poços. As amostras foram caracterizadas de acordo com os teores de salinidade, cálcio, magnésio, bário, estrôncio, sulfato (em mg L $\left.{ }^{-1}\right) . \mathrm{O}$ nível de salinidade foi estimado pela determinação do nível de cloreto por titulometria, o nível de sulfato foi determinado por cromatografia iônica e as outras variáveis foram determinadas por espectrometria de emissão óptica com plasma indutivamente acoplado (ICP-OES). 
Em alguns casos não há dados disponíveis para todas as espécies testadas, então foram consideradas nas análises somente as amostras com no máximo um dado faltante. Nesse caso, utilizou-se o recurso computacional de Not-a-Number $(\mathrm{NaN})$, que permite a realização dos cálculos mesmo na presença de células faltantes. Os dados faltantes nesse caso representam $0,1 \%$ de toda a informação e, portanto, não comprometem os resultados da análise estatística. ${ }^{28}$

Uma amostra de água do mar foi coletada na mesma região dos poços produtores de petróleo e caracterizada utilizando as mesmas metodologias descritas anteriormente. Essa amostra foi utilizada como referência para a água de injeção e foi projetada na análise PCA para fins comparativos.

\section{Estrutura e análise dos dados}

Os dados foram organizados no formato de uma matriz $\mathbf{X}(I, J)$ com $I=609$ amostras coletadas entre Agosto de 2002 e Maio de 2008 nos diferentes poços produtores de petróleo e $J=6$ variáveis químicas em estudo. Os dados foram autoescalados e analisados utilizando PCA. ${ }^{26,27}$ Após a modelagem, uma amostra de referência contendo a composição média da água do mar coletada na região dos poços produtores foi projetada no modelo PCA com o objetivo de comparar a sua composição química com a composição das amostras de água produzida. Os cálculos foram executados utilizando o software PLS Toolbox 5,8 para MatLab 7.8..$^{29,30}$

\section{RESULTADOS E DISCUSSÃO}

\section{Análise exploratória: discriminação dos poços produtores}

A modelagem PCA com 3 fatores forneceu 95,16\% da variância total dos dados (fator $1=63,61 \%$, fator $2=21,90 \%$, fator $3=9,65 \%$ ). Algumas amostras apresentaram valores fora do limite para os parâmetros estatísticos Q e T² de Hotteling (Figura 1), que são utilizados simultaneamente para a detecção de amostras atípicas.

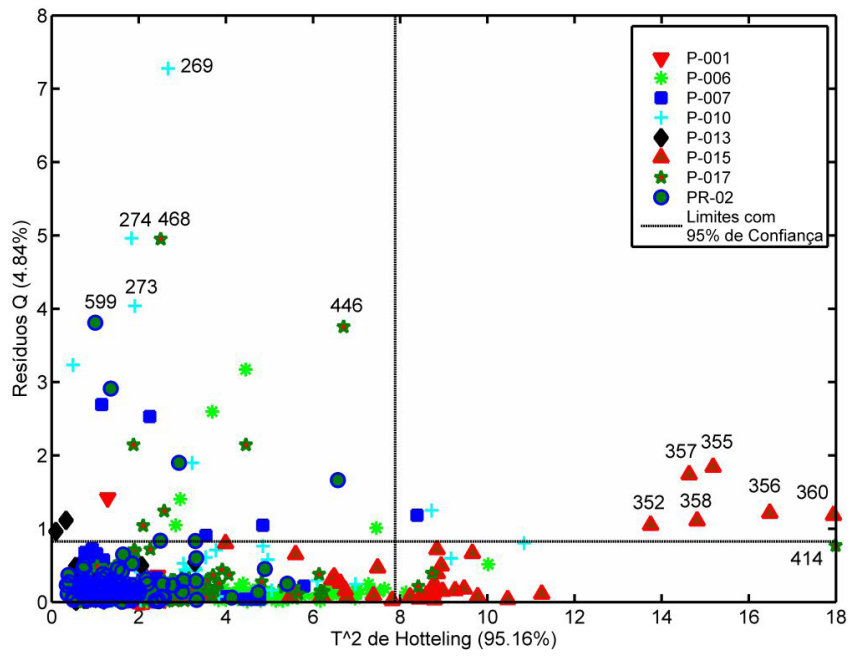

Figura 1. Gráfico dos parâmetros $Q$ e $T^{2}$

O parâmetro Q é a soma quadrática dos resíduos do modelo, e revela a sua falta de ajuste. Para uma dada amostra, o parâmetro Q revela o quanto aquela amostra está contemplada pelo modelo. $\mathrm{O}$ parâmetro $\mathrm{T}^{2}$ de Hotteling expressa a variação de cada amostra dentro do modelo PCA, e é estimado a partir da soma normalizada do quadrado dos escores. ${ }^{31}$ Amostras com comportamento atípico em relação às outras amostras do conjunto tendem a apresentar valores altos para esses dois parâmetros, e devem ser investigadas no sentido de identificar as origens desse comportamento, que em geral está associado a variações não esperadas nas variáveis químicas, e, se possível, buscar no histórico dos dados eventos que possam explicar essas variações. Em estudos exploratórios essas amostras não precisam necessariamente ser excluídas da análise, a não ser que o seu comportamento atípico seja tão acentuado que dificulte a análise do comportamento das outras amostras. Nesse caso, sua retirada é justificada para que seja possível uma melhor visualização das tendências encontradas para as outras amostras.

As amostras 352, 355, 356, 357, 358 e 360 (do poço P-15) apresentaram altos valores de $\mathrm{T}^{2}$ de Hotteling devido ao fato de terem apresentado teores de salinidade, cálcio, magnésio, bário e estrôncio muito acima das outras amostras do mesmo poço. A amostra 414 (do poço $\mathrm{P}$-17) também apresentou valor de $\mathrm{T}^{2}$ relativamente alto, que está associado ao teor de bário muito acima do esperado $\left(250,000 \mathrm{mg} \mathrm{L}^{-1}\right)$ para as amostras do mesmo poço (faixa de bário: 8,500 - 197,000 mg $\mathrm{L}^{-1}$ ). Outras amostras apresentaram valores de resíduos Q muito acima do limite, como por exemplo, as amostras 269, 274 (ambas do poço 10), 446, 468 (ambas do P-17) e 599 (do PR-02), que apresentaram teores de salinidade mais baixos do que o esperado $\left(<65,000 \mathrm{mg} \mathrm{L}^{-1}\right)$ para as amostras de cada classe (faixa de salinidade: $>100.000,000$ $\mathrm{mg} \mathrm{L}^{-1}$ para os dois poços), e a amostra 273 (poço 10) apresentou teor de bário extremamente baixo $\left(<1,000 \mathrm{mg} \mathrm{L}^{-1}\right)$. Apesar do comportamento diferenciado dessas amostras em relação aos valores de Q e $\mathrm{T}^{2}$, esses valores não comprometem a análise do restante do conjunto e, portanto, decidiu-se por mantê-las na modelagem.

Essas coletas foram realizadas ao longo de 7 anos em locais diferentes, e não foi possível levantar todo o histórico dos dados. $\mathrm{O}$ comportamento atípico de algumas amostras pode ter sido causado por intervenções ou problemas de processo nos poços, cujas informações não temos acesso tanto por questões logísticas quanto por questões de confidencialidade. Então, neste momento, podemos apenas identificar que determinadas amostras apresentaram comportamento diferente das suas similares (amostras coletadas na mesma época e para um mesmo poço), e quais foram as variações químicas por elas apresentadas, mas não podemos identificar os eventos históricos associados a essas variações.

As Figuras 2 e 3 contêm os gráficos dos escores para os fatores de 1 a 3, em que é possível observar que cada poço tende a ocupar regiões distintas, ou seja, a apresentar valores característicos de escores.

$\mathrm{Na} \mathrm{PCA}$, os escores são as coordenadas das amostras projetadas num novo sistema de eixos formado pelas componentes principais, e revelam similaridades ou diferenças entre elas, bem como a ocorrência de tendências e amostras com comportamento atípico. ${ }^{26,27}$ Dessa forma, amostras com composição química similar apresentaram valores de escores próximos enquanto amostras diferentes entre si tendem a apresentar valores bem distintos.

O gráfico dos escores apresentou a tendência de formação de seis agrupamentos de amostras (Figura 2a) provenientes dos diferentes poços produtores investigados. Alguns poços, como o P-01 e P-15, apresentaram comportamento bem característico, devido à pouca variabilidade nos valores das variáveis químicas analisadas em cada um deles, que se reflete na pequena variação nos valores dos escores nos 3 fatores. Outros poços, no entanto encontram-se mais dispersos, como é o caso dos poços P-06 e P-07, cujos valores das espécies químicas analisadas apresentaram alta variabilidade. Nesses quatro casos, as amostras de cada poço ocupam regiões distintas entre si, indicando que a composição química de cada poço é bem característica. Outros poços ocupam regiões próximas uns dos outros, apresentando sobreposição de amostras, como é o caso dos poços P-13 e P-17, e P-10 e PR-02 (Figuras $2 \mathrm{a}$ e $2 \mathrm{~b}$ ), indicando alta similaridade na sua composição química.

Os pesos das variáveis descrevem a influência que cada variável original apresenta na construção de cada fator e, portanto, são 

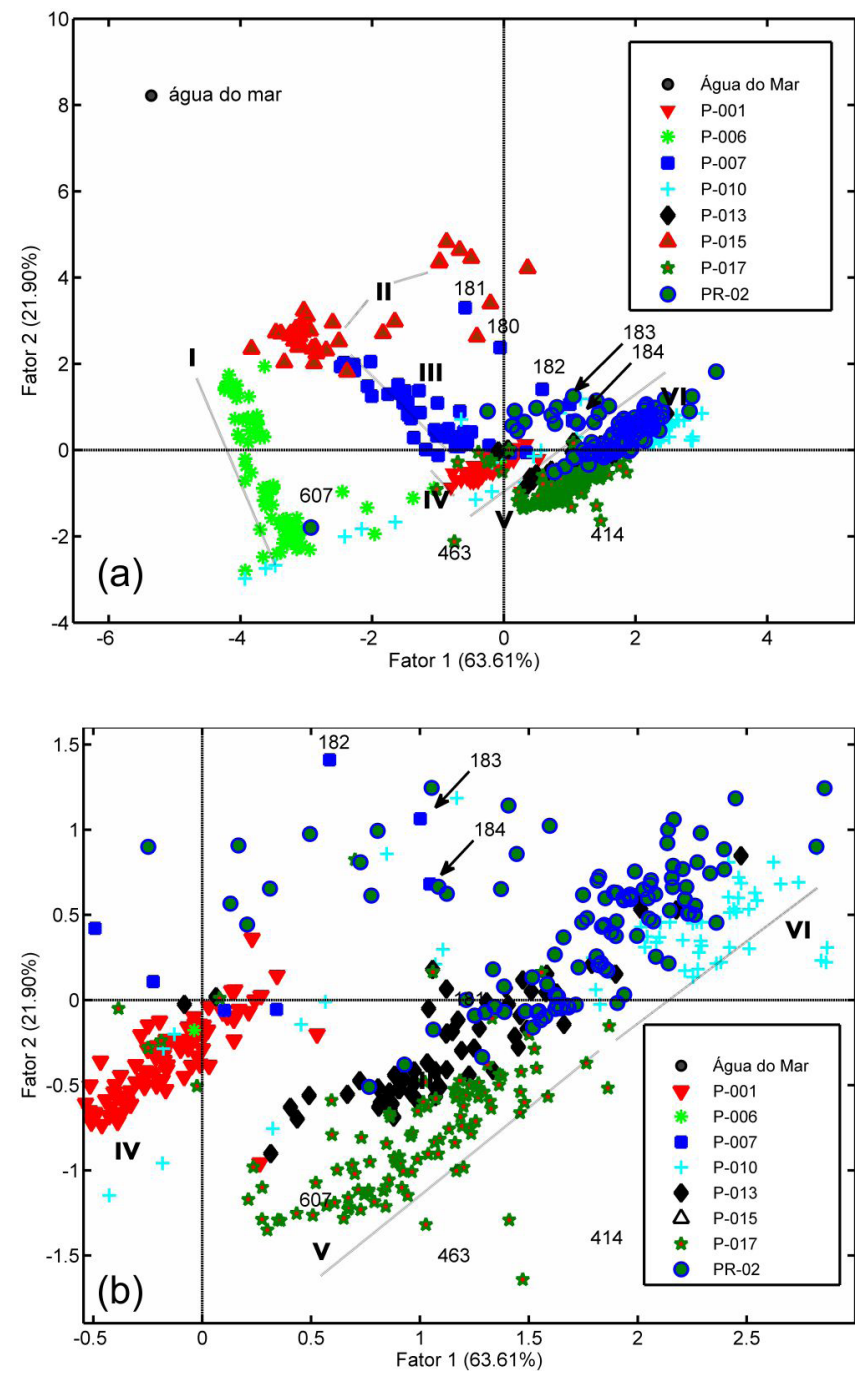

Figura 2. Gráfico dos escores para os fatores (a) 1 e 2 e (b) detalhe, com projeção da amostra de referência (água do mar)

utilizados para interpretar os agrupamentos obtidos no gráfico dos escores. Os pesos são definidos como o cosseno do ângulo entre a variável original e o novo fator, cujos valores encontram-se entre -1 a 1. Isso significa que variáveis com pesos próximos de \pm 1 apresentam alta contribuição num determinado fator, enquanto pesos próximos a zero não têm influência. Da mesma forma, pesos positivos indicam que existe uma relação de proporcionalidade direta entre o valor da variável original e o valor do escore, ou seja, uma variável com alto peso positivo em determinado fator indica que o teor da variável em questão tende a aumentar proporcionalmente ao valor do escore no mesmo fator. O inverso vale para os pesos negativos. ${ }^{26,27} \mathrm{~A}$ modelagem PCA encontrou que o fator 1 descreve a variação nos teores de salinidade (peso $=0,467)$, cálcio $($ peso $=0,484)$ e estrôncio $($ peso $=$ $0,498)$, o fator 2 está associado às variáveis magnésio (peso $=0,783$ ) e sulfato $(0,564)$, com maior influência do magnésio, que apresentou maior valor de peso, e o fator 3 à variável bário (peso = 0,891). Desta forma, o uso dos três fatores permite avaliar a influência das seis variáveis originais na distribuição das amostras no espaço descrito pelas três componentes principais utilizadas, ou seja, a dimensão do conjunto de dados diminuiu de seis (número de variáveis originais) para três (número de fatores utilizados na análise).

A água de formação contém teores mais altos de salinidade, cálcio e estrôncio do que a água do mar, enquanto essa última é rica em magnésio e sulfato. ${ }^{7-12}$ Para os poços produtores que receberam
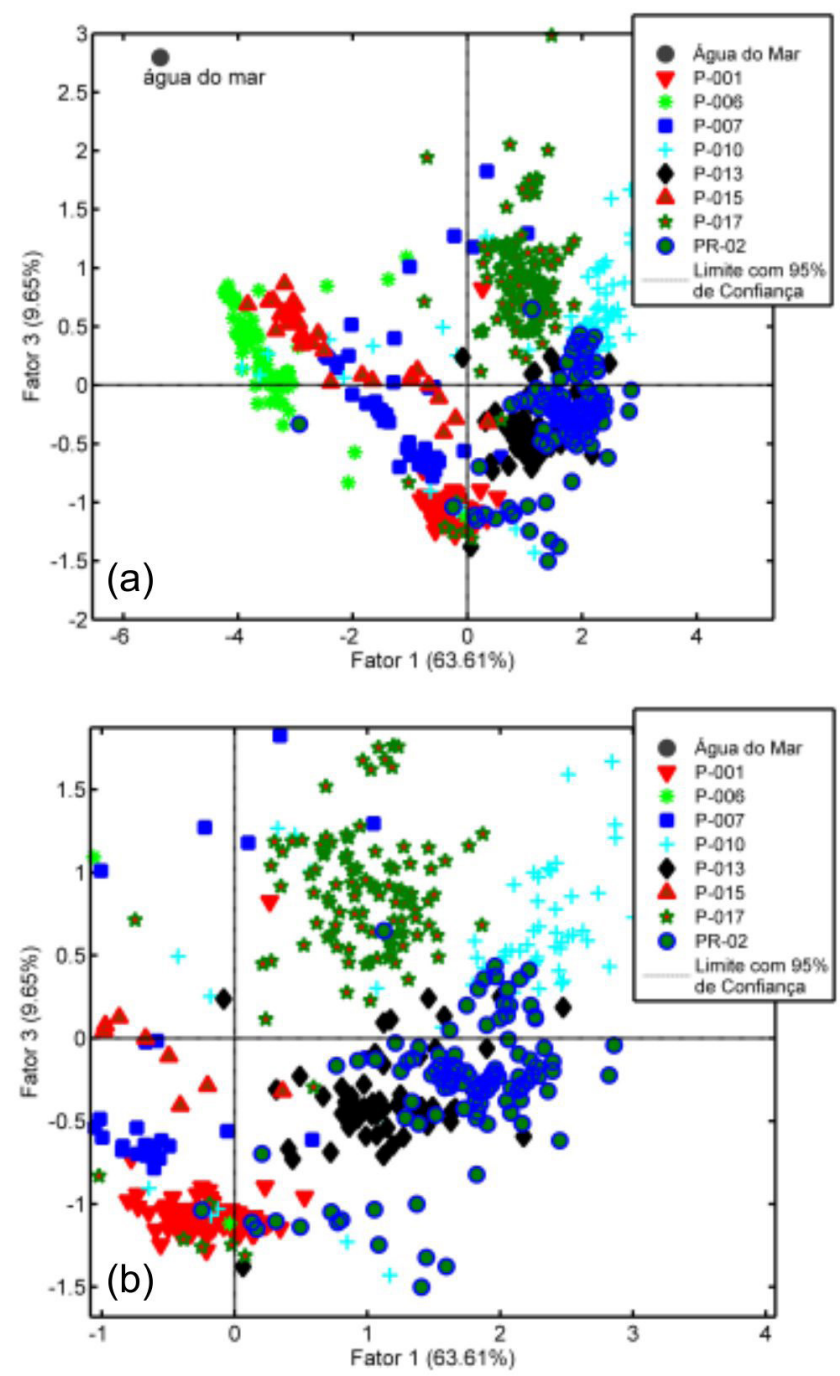

Figura 3. Gráfico dos escores para os fatores (a) 1 e 3 e (b) detalhe, com projeção da amostra de referência (água do mar)

injeção de água do mar (P-06 e P-07), a variação dos teores destas variáveis em função do tempo é claramente observada (Figuras 4 e 5).

Sendo assim, as variáveis salinidade, cálcio e estrôncio poderão ser utilizadas em conjunto na forma dos escores das amostras no fator 1, como traçadores para água de formação. Da mesma forma a associação das variáveis magnésio e sulfato, na forma dos escores das amostras no fator 2 poderá ser utilizada como traçador para a água do mar. ${ }^{7,12,32}$ A concentração de bário tende a ser baixa na água do mar e alta na água de formação e tende a diminuir com o tempo nos poços que receberam água de injeção. No entanto, essa espécie tende a formar precipitados salinos na presença de excesso do ânion sulfato, que reduz a quantidade de bário disponível na água e, portanto, o seu uso como traçador de água de formação não é confiável. Contudo, a queda abrupta nos níveis de bário na presença de altas concentrações de sulfato poderá estar associada com a formação de incrustações salinas nas tubulações do processo, e deverá ser investigada para viabilizar a tomada de ações preventivas. ${ }^{7,12,32}$

De forma geral, a análise do gráfico dos escores revelou a existência de seis perfis químicos de amostras, que encontram-se descritos a seguir.

- Perfil I: formado pelas amostras do poço P-06, que apresentaram os menores teores de salinidade, cálcio e estrôncio de todo o conjunto, como é possível observar pelos baixos valores de escores no fator 1 . Os teores dessas variáveis apresentam uma 

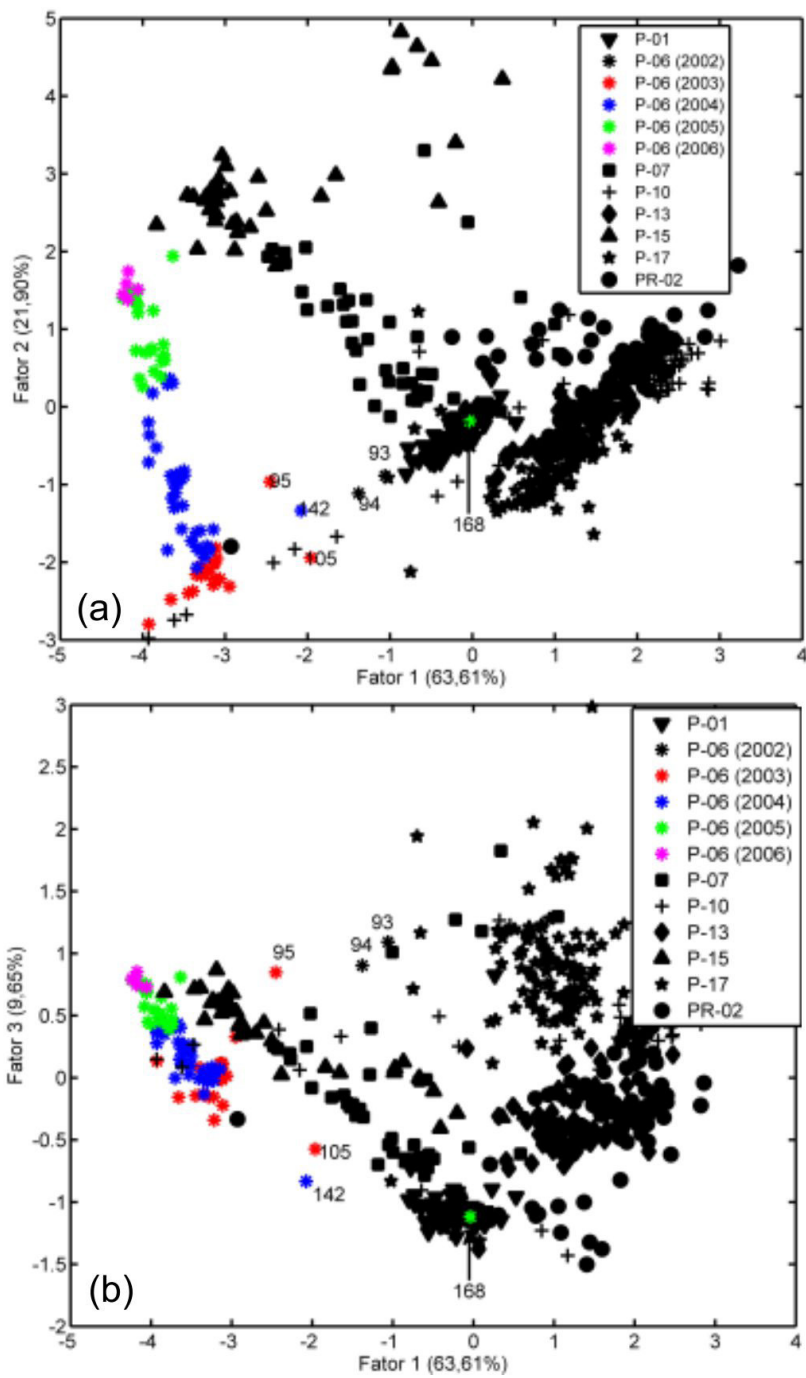

Figura 4. Detalhe do gráfico dos escores para os fatores (a) 1 e 2 e (b) 1 e 3, mostrando as tendências sazonais do poço P-06

pequena variação, o que é mostrado pela pequena variação nos valores dos escores, e tendem a diminuir com o tempo ( Figuras 2a e 4). As amostras desse poço apresentaram uma ampla faixa de teores de magnésio e sulfato, que pode ser visualizada pela grande variação dos valores de escores no fator 2 (Figura 2), e que aumentam acentuadamente com o tempo (fator 2, Figura 4) devido à injeção de água do mar. Detalhes dos aspectos sazonais podem ser observados na Figura 4. Essas amostras apresentaram ainda uma faixa ampla de teores de bário, com valores considerados intermediários quando comparados às amostras dos outros poços (Figura 3).

- Perfil II: formado pelas amostras do poço P-15, que apresentou teores intermediários de salinidade, cálcio e estrôncio, descritos pelos valores dos escores dessas amostras no fator 1 (Figura 2). Esse poço apresentou os maiores teores de magnésio e sulfato de todo o conjunto, conforme mostram seus altos valores de escores no fator 2 (Figura 2), o que indica que, dentre os poços analisados, foi o que apresentou a composição mais parecida com a composição média da água do mar. As amostras deste poço se dividem em dois subconjuntos relacionados aos teores de salinidade, cálcio e estrôncio (descritos pelo fator 1) e magnésio, (descrito pelo fator 2), que foram maiores para as amostras coletadas nos anos de 2004 e 2005 (são as amostras com valores mais altos de escores nestes dois fatores. Os teores de bário (fator 3 ) variaram
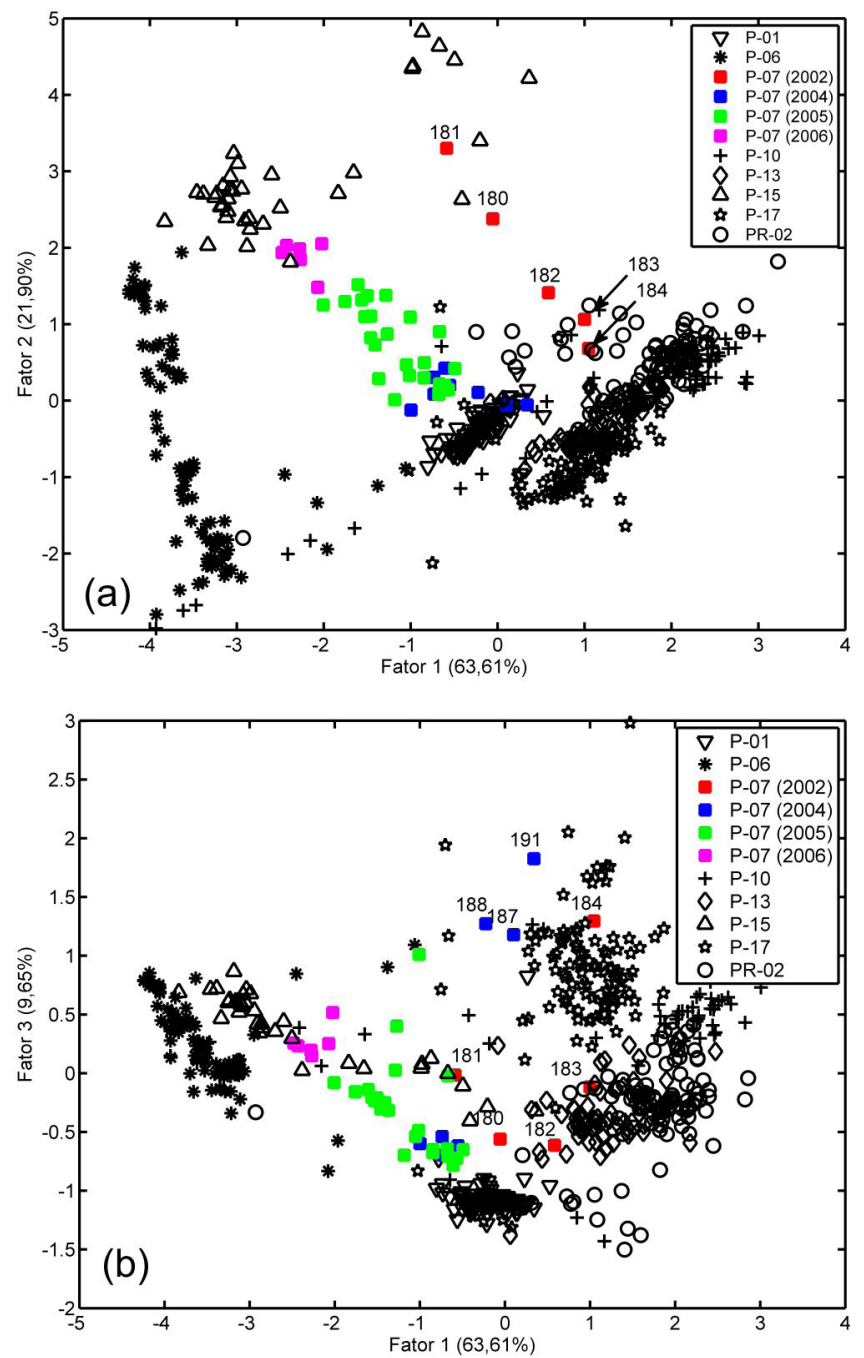

Figura 5. Detalhe do gráfico dos escores para os fatores (a) 1 e 2 e (b) 1 e 3, mostrando as tendências sazonais do poço P-07

pouco para este poço (Figura 3, Figuras $1 \mathrm{~S}$ e $2 \mathrm{~S}$ do Material Suplementar).

- Perfil III: formado pelas amostras do poço P-07, que apresentou ampla faixa de valores para as variáveis salinidade, cálcio e estrôncio, como descrito nos escores do fator 1 e para as variáveis magnésio e sulfato, descritas pelo fator 2 (Figura 2). Esse poço recebeu injeção de água do mar, e é possível observar no gráfico dos escores a queda acentuada nos teores de salinidade, cálcio e estrôncio ao longo do tempo, assim como o aumento nos teores de magnésio e sulfato (Figuras 2a e 5a). Cinco amostras (180, $181,182,183$ e 184) desse poço diferem um pouco das outras, pois tendem a apresentar teores mais altos do que os esperado para as variáveis salinidade, cálcio e estrôncio (descritas pelo fator 1). Essas amostras foram as primeiras a serem coletadas, em 2002, quando o poço entrou em operação e passou a receber injeção de água do mar, que possui baixos teores dessas variáveis, diminuindo abruptamente, portanto, estes teores nas amostras subsequentes. Os teores de bário apresentaram pouca variabilidade, aumentando ligeiramente para as amostras coletadas nos anos de 2005 e 2006 (Figura 5b), com exceção de algumas poucas amostras que apresentaram valores muito acima do esperado (184, 187, 188 e 191).

- Perfil IV: formado pelas amostras do poço P-01, que apresentou pouca variabilidade nos teores de salinidade, cálcio e estrôncio 
(fator 1) e magnésio e sulfato (fator 2) quando comparadas às amostras dos outros poços, como pode ser observado pelos valores dos escores nos fatores 1 e 2, respectivamente, (Figura 2). As amostras deste poço apresentaram correlação positiva entre as variáveis descritas pelos fatores 1 e 2 , ou seja, os teores de salinidade, cálcio e estrôncio (fator 1) aumentam em função do aumento dos teores de magnésio e sulfato (fator 2). As amostras desse poço apresentaram uma estreita faixa de valores de bário, como pode ser observado pelos valores de escores no fator 3 , Figura 3, Figuras 1S e 2S do Material Suplementar).

- Perfil V: formado pelos poços P-13 e P-17 (Figuras 2a e 2b), cujas amostras apresentaram perfil semelhante, e muito próximo do perfil das amostras do poço P-01, se distinguindo destas apenas pelos teores mais altos de salinidade, cálcio e estrôncio, descritos pelos escores do fator 1 . De forma geral, as amostras dos poços P-13 e P-17 apresentaram teores ligeiramente mais altos de salinidade, cálcio e estrôncio, e teores intermediários de magnésio e sulfato, que apresentaram uma variabilidade baixa quando comparadas às amostras dos outros poços, como pode ser visualizado no fator 2 . A análise dos valores de escores do fator 3 identificou que o poço P-17 apresentou teores de bário mais altos do que o poço P-13 (Figura 3, Figuras 1S e 2S do Material Suplementar).

- Perfil VI: formado pelos poços P-10 e PR-02 (Figura 2a e 2b), que apresentaram os maiores teores de salinidade, cálcio e estrôncio de todo o conjunto, e teores intermediários de magnésio e sulfato, que estão associados aos valores de escores dos fatores $1 \mathrm{e}$ 2 , respectivamente. Algumas amostras do poço PR-02 formam um agrupamento ligeiramente separado das outras amostras do mesmo poço, com teores de salinidade, cálcio e estrôncio mais baixos do que o esperado, o que pode ser visualizado nos menores valores de escores do fator 1 para estas amostras (Figura 2). Essas amostras também apresentaram teores de bário mais baixo do que as outras amostras do grupo, detectado pelos seus baixos valores de escore no fator 3 (Figura 3). O teor de bário (fator 3) é responsável pela distinção entre os dois poços, sendo que o poço P-10 apresentou níveis mais altos para essa variável, e que tendem a diminuir com o tempo (Figura 3, Figuras $1 \mathrm{~S}$ e 2S do Material Suplementar).

\section{Padrões de sazonalidade: efeitos da injeção de água do mar nos} poços P-06 e P-7

Os teores de salinidade, cálcio e estrôncio (descritos pelo fator 1) são proporcionais aos teores de magnésio e sulfato (descritos pelo fator 2) para os poços P-01, P-13, P-17 e PR-02 (Figuras 2a e 2b, Figura 1S do Material Suplementar). Em geral, os teores dessas variáveis para os poços P-01, P-17 e PR-02 tendem a aumentar nos primeiros anos de atividade do poço, ou seja, no início das operações de extração, até atingirem um patamar relativamente constante para os anos seguintes. Esses poços também apresentaram teores decrescentes de bário no início das atividades de extração, atingindo um patamar constante nos anos seguintes (fator 3, Figura 2S do Material Suplementar), com exceção do poço P-01, que não apresentou padrão sazonal relacionado a essa variável.

Já os poços P-06 e P-07, que receberam injeção de água do mar, apresentaram um comportamento sazonal bem acentuado, com teores crescentes de magnésio e sulfato ao longo dos anos, e teores decrescentes de salinidade, cálcio e estrôncio (Figuras 4 e 5). Para o poço P-06, a amostra 168 (coletada em 2005) apresentou teores de salinidade, cálcio e estrôncio extremamente altos para o perfil do poço. Além dela, as amostras 93 e 94 (coletadas em 2002), 95 e 105 (2003), 142 (2004) apresentaram teores de salinidade, cálcio e estrôncio relativamente maiores do que o esperado. Para o poço P-07, as amostras coletadas em 2002, no início das atividades do poço, apresentaram teores altos de salinidade, cálcio e estrôncio (fator 1), e ampla faixa de variação nos teores de magnésio (fator 2). Nos dois casos os teores de bário (fator 3) apresentaram um ligeiro aumento em função do tempo (Figura 4b). As amostras 184, 187, 188 e 191 do poço P-07 apresentaram teores de bário acentuadamente mais altos do que o esperado. Padrões sazonais não foram identificados para os poços P-10 e P-15.

\section{Água do mar: comparação da água produzida dos poços com amostra de referência}

A amostra de referência contendo a composição média da água do mar da região dos poços produtores de petróleo (salinidade $=$ $35.000,00 \mathrm{mg} \mathrm{L}^{-1}$, cálcio $=504,000 \mathrm{mg} \mathrm{L}^{-1}$, magnésio $=1.390,000$ $\mathrm{mg} \mathrm{L} \mathrm{L}^{-1}$, bário $=1,000 \mathrm{mg} \mathrm{L}^{-1}$, estrôncio $=9,000 \mathrm{mg} \mathrm{L}^{-1}$ e sulfato $=$ 2.834,000 $\mathrm{mg} \mathrm{L}^{-1}$ ) foi projetada na modelagem PCA. As Figuras $2 \mathrm{e}$ 3 contêm o gráfico dos escores, em que é possível notar a composição característica da amostra de referência, que apresentou os menores teores de salinidade, cálcio e estrôncio (fator 1), e os maiores teores de magnésio e sulfato (fator 2) quando comparada às amostras de água produzida. Como observado anteriormente, nos poços em que ocorreu injeção de água do mar (P-06 e P-07), é possível observar claramente o aumento de magnésio e sulfato, e a diminuição dos teores de salinidade, cálcio e estrôncio com o passar do tempo (Figuras 4 e 5). A amostra de referência aparece na região dos valores altos de escores do fator 3, que descreve a influência da variável bário. Isso indica que o teor de bário para essa amostra é maior do que para as amostras de água produzida, o que não era esperado, pois o teor de bário para esta amostra é baixo $\left(1 \mathrm{mg} \mathrm{L}^{-1}\right)$. Para investigar em detalhes o comportamento não usual desta amostra em relação aos escores do fator 3, foi construído um gráfico do teor de bário em função dos escores do fator 3 (Figura 6), em que nota-se que o teor de bário é proporcional aos escores desse fator somente para as amostras dos poços produtores $\mathrm{P}-10, \mathrm{P}-13, \mathrm{P}-17$ e PR-02, que apresentaram teores de bário acima de $50 \mathrm{mg} \mathrm{L}^{-1}$, e cujos valores dessa variável tende a diminuir com o tempo (Figuras $1 \mathrm{~S}$ e $2 \mathrm{~S}$ do Material Suplementar).

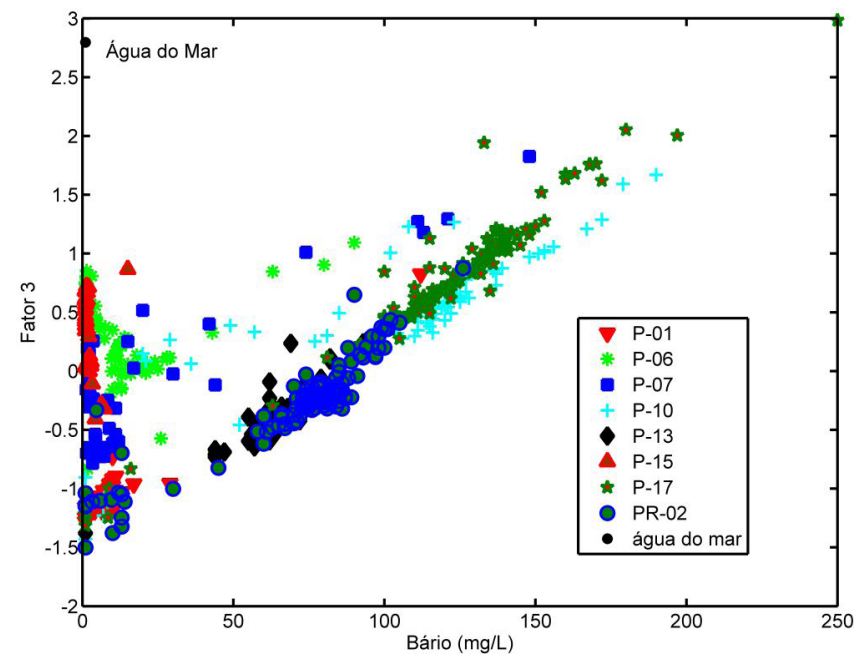

Figura 6. Gráfico de teor de bário $(\mathrm{mg} / \mathrm{L})$ vs. escores do fator 3

\section{CONCLUSÕES}

O uso do método PCA permitiu a identificação das variáveis salinidade, cálcio e estrôncio, quando utilizadas em conjunto, como traçadores da água de formação, e as variáveis magnésio e sulfato 
como traçadores de água do mar. Pela análise dos escores das amostras foi possível acompanhar as variações sazonais do perfil químico das amostras dos poços produtores que receberam injeção da água do mar (P-06 e P-07), bem como a identificação da tendência a separação das amostras em 6 grupos em função das variáveis químicas estudadas, e algumas amostras com comportamento atípico. Os poços com teores de bário acima de $50 \mathrm{mg} \mathrm{L}^{-1}$ apresentaram o padrão esperado para os teores de bário, que tendem a diminuir com o tempo. São eles: P-10, P-13, P-17 e PR-02. O mesmo comportamento não foi observado nos poços P-01, P-06, P-07 e P-15, que apresentaram teores mais baixos de bário.

As amostras dos poços produtores foram comparadas com uma amostra contendo o perfil médio da água do mar da região. Essa amostra apresentou baixos valores de escores no fator 1 (associados à salinidade, cálcio e estrôncio) e altos valores no fator 2 (associados à magnésio e sulfato), confirmando os resultados obtidos anteriormente.

\section{MATERIAL SUPLEMENTAR}

Detalhes dos gráficos dos escores para os fatores 1, 2 e 3, mostrando as tendências sazonais dos poços P-01, P-10, P-13, P-15, P-17 e PR-02, são mostrados nas Figuras $1 \mathrm{~S}$ e $2 \mathrm{~S}$ do material suplementar, que estão disponíveis em http://quimicanova.sbq.org.br, em arquivo pdf, com acesso livre.

\section{REFERÊNCIAS}

1. http://www.brasil.gov.br/sobre/economia/energia/petroleo-gas-naturale-derivados/petroleo-e-derivados, acessada em Julho 2013.

2. http://www.petrobras.com.br/rs2012/downloads/RS_português_2012. pdf, acessada em Julho 2013.

3. http://pt.wikipedia.org/w/index.php?title=Petrobras\&oldid=35439971, acessada em Julho 2013

4. http://pt.wikipedia.org/w/index.php?title=Camada_pr\%C3\%A9sal\&oldid=35610784, acessada em Julho 2013.

5. http://www.petrobras.com.br/pt/quem-somos/estrategia-corporativa/ plano-de-negocios/, acessada em Julho 2013.

6. Ak, R.; Li, Y.F.; Vitelli, V.; Zio, E.; Droguett, E. L.; Jacinto, C. M. C.; Expert Syst. Appl. 2013, 40, 1205.

7. Webb, P. J.; Kuhn, O.; International Symposium on Oilfield Scale-Soc. Pet. Eng. (SPE 87458), Aberdeen, UK, 2004.
8. Bader, M. S. H.; J. Pet. Sci. Eng. 2007, 55, 93.

9. El-Said, M.; Ramzi, M.; Abdel-Moghny, T.; Desalination 2009, 249, 748.

10. Dudášová, D.; Flåten, G. R.; Sjöblom, J.; Øye, G.; J. Colloid Interface Sci. 2009, 337, 464.

11. Puntervold, T.; Austad, T.; J. Pet. Sci. Eng. 2008, 63, 23.

12. Teixeira, H. M. F., Tese de Doutorado, Pontifícia Universidade Católica do Rio de Janeiro, Brasil, 2007.

13. Bahadori, A.; Al-Haddabi, M.; Vuthaluru, H. B.; Pet. Sci. Technol. 2013, 31,691 .

14. http://www.arth-altuna.com/docs/DICCIONARIO\%20GEOLOGICO. pdf, acessada em Julho 2013.

15. McFarlane, J.; Sep. Sci. Technol. 2005, 40, 593.

16. Kloppmann, W.; Matray, J. M.; Aranyossy, J. F.; Appl. Geochem. 2001, $16,1083$.

17. Jerez Vegueria, S. F.; Godoy, J. M.; Miekeley, N.; J. Environ. Radioact. 2002, 62, 29.

18. Sirivedhin, T.; Dallbauman, L.; Chemosphere 2004, 57, 463

19. Birkle, P.; García, B. M.; Padrón, C. M. M.; Eglington, B. M.; Appl. Geochem. 2009, 24, 543.

20. Birkle, P.; García, B. M.; Padrón, C. M. M.; Eglington, B. M.; Appl. Geochem. 2009, 24, 555

21. Remeljef, C. W.; Asia Pacific Oil and Gas Conference - Soc. Pet. Eng. (SPE 28796), Melbourne, Australia, 1994.

22. Alfarhan, A. A.; Duane, M. J.; Arab. J. Geosci. 2012, 5, 1055.

23. Barbot, E.; Vidic, N. S.; Gregory, K. B.; Vidic, R. D.; Environ. Sci. Technol. 2013, 47, 2562.

24. Grasby, S. E.; Chen, Z. H.; Dewing, K.; Appl. Geochem. 2012, 27, 1623.

25. Ribeiro, F. A. L.; Rosário, F. F. R; Bezerra, M. C. M.; Bastos, A. L. M.; Melo, V. L. A.; Poppi, R. J.; Chemom. Intell. Lab. Syst. 2012, 115, 18.

26. Wold, S.; Esbensen, K.; Geladi, P., Chemom. Intell. Lab. Sys. 1987, 2 , 37.

27. Beebe K. R., Pell R. J., Seasholtz, M. B.; Chemometrics: A practical guide, John Wiley \& Sons: New York, 1998.

28. Walczak, B.; Massart, D. L.; Chemom. Intell. Lab. Syst. 2001, 58, 15.

29. PLS Toolbox 5.8, Eigenvector Research, Inc., USA, 2010.

30. MatLab 7.8, The MathWorks Inc., USA, 2009.

31. Wise, B.; Gallangher, N. B.; Bro, R.; Shaver, J. M., PLS Toolbox 3.0, for use with MATLAB ${ }^{T M}$ - Manual, Eigenvector Research, Inc., USA, 2005.

32. BinMerdhah, A. B.; Yassin, A. A. M.; Muherei, M. A.; J. Pet. Sci. Eng. 2010, 70, 79 . 


\section{PCA: UMA FERRAMENTA PARA IDENTIFICAÇÃO DE TRAÇADORES QUÍMICOS PARA ÁGUA DE FORMAÇ̃̃̃O E ÁGUA DE INJEÇÃO ASSOCIADAS À PRODUÇÃO DE PETRÓLEO}

Fabiana Alves de Lima Ribeiro*\#, Guilherme Alvarenga Mantovani ${ }^{*}$ e Ronei Jesus Poppi ${ }^{*}$

Instituto de Química, Universidade Estadual de Campinas, Cidade Universitária Zeferino Vaz, CP 6154, 13083-970 Campinas SP, Brasil

Francisca Ferreira do Rosário, Maria Carmen Moreira Bezerra, Andre Luis Mathias Bastos e Vera Lúcia Alves de Melo Centro de Pesquisas e Desenvolvimento Leopoldo Américo Miguez de Mello, Petróleo Brasileiro S.A., Av. Horácio Macedo, 950 - Cidade Universitária, 21941-915 Rio de Janeiro - RJ, Brasil
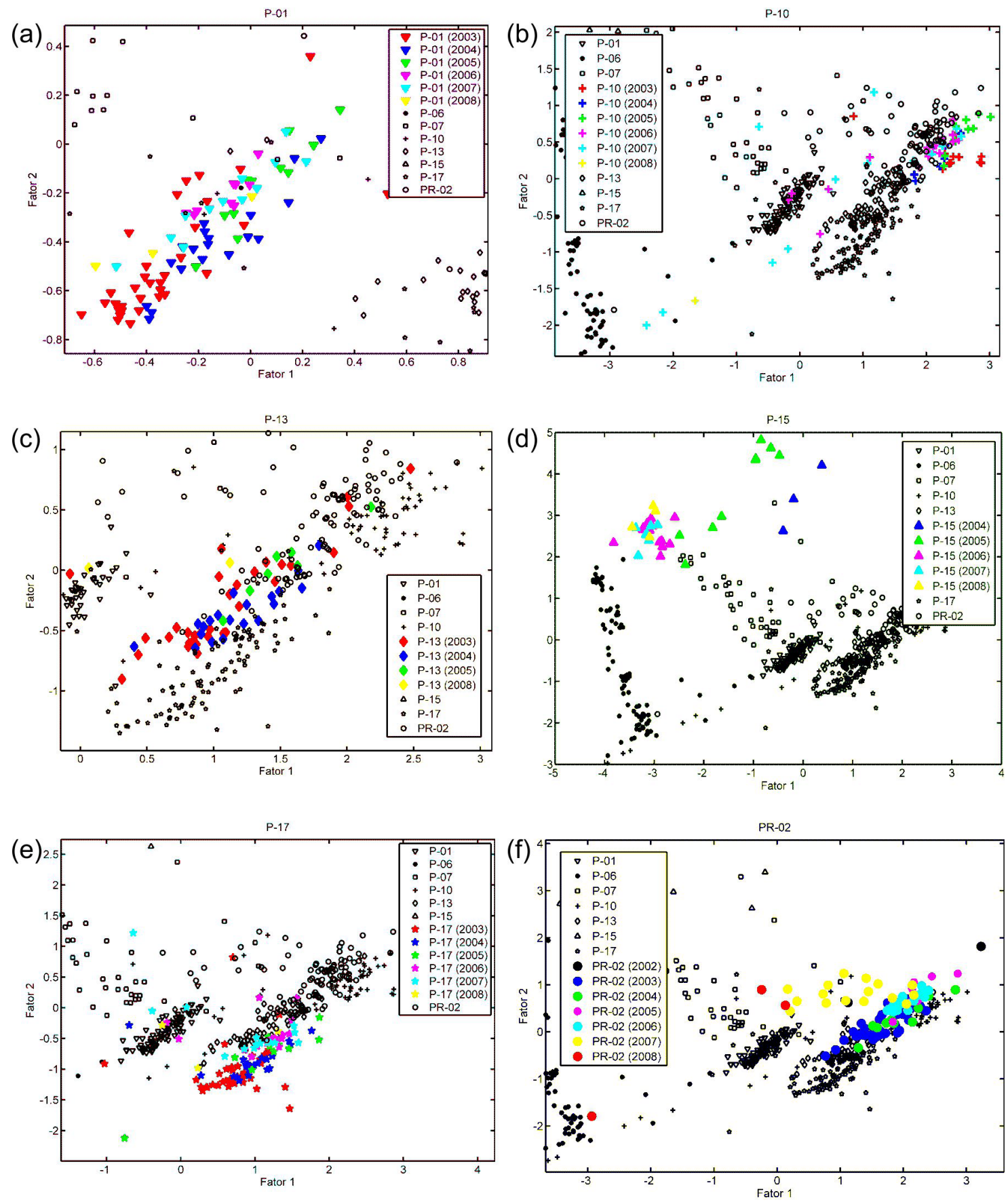

Figura 1S. Detalhe do gráfico dos escores para os fatores 1 e 2, mostrando as tendências sazonais dos poços (a) P-01, (b) P-10, (c) P-13, (d) P-15, (e) P-17 e (f) $P R-02$ 

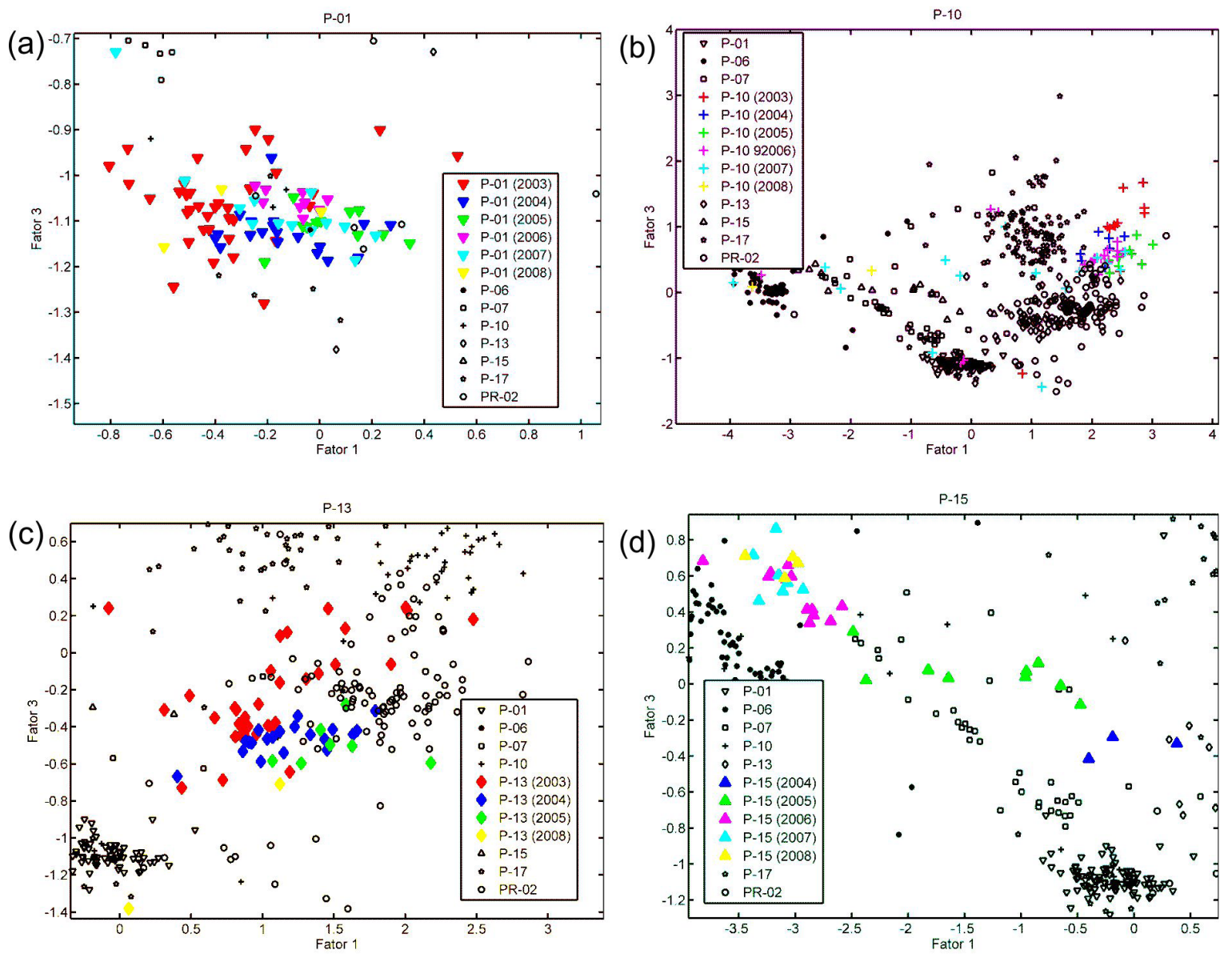

(f)
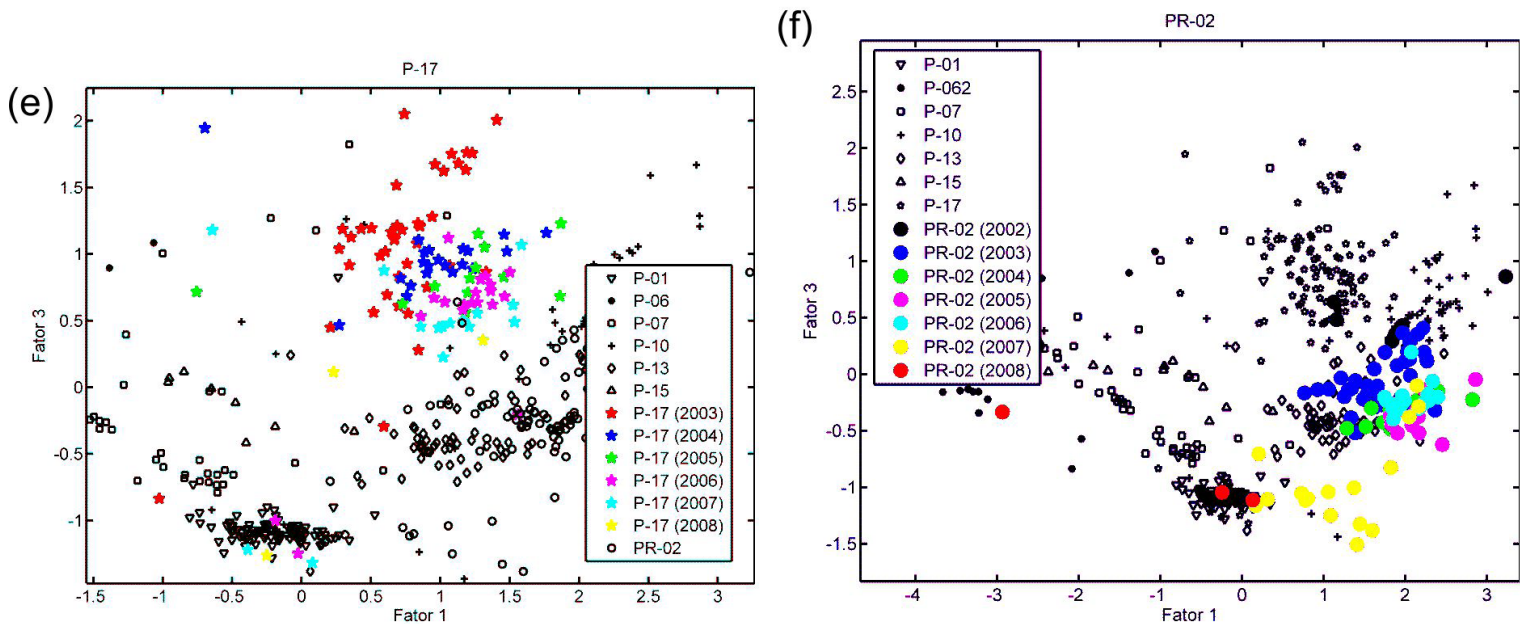

Figura 2S. Detalhe do gráfico dos escores para os fatores 1 e 3, mostrando as tendências sazonais dos poços (a) P-01, (b) P-10, (c) P-13, (d) P-15, (e) P-17 e (f) PR-02 